\title{
Last held Military Rank and Wellbeing (Psychological Distress) of Army Ex-Servicemen (Non-Commissioned Officers)
}

\author{
Rajesh Verma ${ }^{1} *$, Prof Rajbir Singh ${ }^{2}$
}

\section{ABSTRACT}

The soldiers in civil life after separation from military service are more or less designated as Exservicemen. The uniqueness of their service requirements and job profile they regularly faces life altering events in their daily life. Their behavior is likely to have significant footprints of these events for longer time. To assess the remains of impact of military service on the behavioural platform of these semi soldiers a sample of 70 Ex-servicemen (non-commissioned ranks) were purposely selected and assigned into two groups as per their rank. GHQ 12 was used to assess the wellbeing (psychological distress). The findings suggested that there is significant effect of rank on the measured variable which might be attributed to several factors couple of them are demands of unyielding orders \& commands and regular exposure to intense violence. However, it is pertinent to mention here that the result of the study is required to be tested across the country with larger samples drawn from the population of interest prior to generalization and ascertaining its' validity and reliability. Constructive suggestions and criticism will be highly appreciated and in fact solicited.

Keywords: Military Rank, Wellbeing, Army

\section{Rationale of the Study}

1. This subject is closely related to my doctorate topic i.e. "General wellbeing, adjustment and achievements in civil life vis-à-vis personal resources and demands of noncommissioned officers of army ex-servicemen".

2. The studies on Indian Ex-servicemen (non commissioned officers) are exceptionally rare.

3. This lot of 'semi soldiers' needs to be accorded with academic attention due to them, this study is an attempt in that direction.

\footnotetext{
${ }^{1}$ Ph.D, Research Scholar, MD University, Rohtak, India

${ }^{2}$ Professor, Department of Psychology, MD, University, Rohtak, India

*Responding Author

(C) 2016, R Verma, R Singh; licensee IJIP. This is an Open Access Research distributed under the terms of the Creative Commons Attribution License (http://creativecommons.org/licenses/by/2.0), which permits unrestricted use, distribution, and reproduction in any Medium, provided the original work is properly cited.
} 


\section{Last held Military Rank and Wellbeing (Psychological Distress) of Army Ex-Servicemen (Non- Commissioned Officers)}

\section{INTRODUCTION}

In simplest terms an Ex-serviceman is "A soldier who had completed coloured service in defence services for a specified time period and suitable to draw pension from consolidated public fund of India”. Ex-servicemen are lawfully separated soldiers of army. Armies worldwide follow a rigid hierarchical system of ranks to manage and organize humans having high degree of individual behavioural variance. Rank in army is a professional identifier having profound significance on the holder's behavioural outcomes. It is a position bestowed to soldiers signifying holder's importance and scope of responsibility. Rank defines soldier's professional and social standing within and outside (social set up) the institution. Traditionally, in defence parlance it is understood that Rank never retires; only individual retires. In this backdrop Exserviceman continue to decorate their names with last held rank. Military rank is a base professional and functional management tool helps in managing soldier's behaviour, interpersonal relations, and shared as well as individual responsibilities, most importantly rank takes care of self-esteem while preserving individual identity. Ex-serviceman is a semi soldier.

Post retirement, rank is reminiscent of dignity, power and prestige enjoyed during the active service. In addition to professional significance, the rank is also endowed with psycho-social stature. Army has two types of exclusive 'Rank' system one for no- commissioned officers and other for commissioned officers. The present study is focused on the retired non-commissioned officers (Subedar Major and below) of Indian army. Post retirement is a new phase in the life of Ex-serviceman. Retirement at young age has its own hazards and gains. Retirement is a kind of job loss which puts tremendous pressure on financial resources of the retiree engendering a negative stress commonly known as distress. The distress owing to weak financial resources takes its toll on wellbeing and other behavioural aspects.

General wellbeing is a general health and happiness, blend of emotional, psychological, spiritual and physical being. The concept of general wellbeing (psychological) in context of this study is limited to psychological distress, the most important contributing factor for overall wellbeing. Carol et al. (1995) in their study explored several dimensions of well being out of which they found “Autonomy, Positive Relations with Others, Self-Acceptance, Environmental Mastery, Purpose in Life, and Personal Growth” are of considerable importance in managing the well being of individual.

Armies are primarily constituted for the business of violence management where soldiers are constantly exposed to exceptional psychosomatic and health related problems. These soldiers when retire carry these cognitive traces along with them in their second innings of life. When they separates from army and subsequently become ESM, they are found to be afflicted or on the threshold of affliction of various formally recognized disorders like Post Traumatic Stress Disorder (PTSD), mental well being related issues, clinical depression, adjustment disorders,

(c) The International Journal of Indian Psychology, ISSN 2348-5396 (e)| ISSN: 2349-3429 (p) | 193 


\section{Last held Military Rank and Wellbeing (Psychological Distress) of Army Ex-Servicemen (Non- Commissioned Officers)}

psychological distress, bi-polar disorder, and several other whole health issues (Kelly, 2012). When unnoticed which is most likely, they take a great toll on their life as well as on society as a whole. The individual in particular and the society in general faces grave risk of disturbances owing to transited personal troubles. Several other factors, which are found to be common among retired military personnel are perceived stress of transition, sudden loss of source of income, fear of rejection, family obligations, demand resources (both psychological and physical) mismatch etc. (Hamlet-Trust, 2009). The ex-military men are prone to profession related mental problems such as PTSD (Carpenter, 2009) which causes many to sink into alcoholism, drug addiction, and reclusive lifestyles or sometimes takes extreme step of taking one's life (Media Release, Australia, 2008). The other general wellbeing problems attributed to active duty which transits even after retirement includes psychological fatigue, distress, depression, Alcohol Dependency Syndrome, anxiety, combat stress (Pemberton, 2012).

\section{Hypothesis}

1. There is significant difference between JCOs and Other ranks (last held Military Rank) on wellbeing (psychological distress).

\section{Objective}

2. To explore the relationship between the last held military rank by Ex-servicemen and wellbeing (psychological distress) its significance.

\section{METHODOLOGY}

\section{Sample}

The 70 Ex-servicemen (35 JCOs and 35 Other ranks) with average age 50.37 and 40.26 years respectively. The Ex-servicemen who retired without any disability pension were selected from three districts (Hisar, Fatehabad and Sirsa) of Haryana.

\section{Procedure}

The contact details were obtained from respective Zila Sainik Boards. Afterwards the Exservicemen were personally contacted on their mobile phones for fixing of date for data collection. The data were collected after obtaining written consent on a prescribed format. It was purposive sample. The sample was assigned into two groups on the basis of their last held military rank. The purpose of the study was briefly explained to each participating Exserviceman before handing over the GHQ-12 performa. The data was analysed by one way ANOVA.

Group I: This group consisted of retired Junior Commissioned Officer popularly known as JCOs of Indian Army i.e. those who retired in the rank of Naib Subedar, Subedar and Subedar Major.

(C) The International Journal of Indian Psychology, ISSN 2348-5396 (e)| ISSN: 2349-3429 (p) | 194 


\section{Last held Military Rank and Wellbeing (Psychological Distress) of Army Ex-Servicemen (Non- Commissioned Officers)}

Group II: This group consisted of retired Other_ranks popularly known as ORs of Indian Army i.e. who retired holding the rank of Sepoy, Lance Naik, Naik and Havildar.

\section{Tools used}

Wellbeing (psychological distress) was assessed using General Health Questionnaire-12 Hindi version translated by Gautam et al. (1987). The reliability of the test was checked by 'translation retranslation' technique established to be $96 \%$ and split half method $(\mathrm{N}=500)$ using Pearson ' $\mathrm{r}$ ' correlation method which was found to be 0.78 . GHQ deals with two dimensions: helplessness to carry on normal 'healthy' functions, and the emergence of a new psychological painful occurrence. GHQ-12 contains 12 items which are to be responded on 4 point scale which is an effective case detector. "It is a pure state measure rather than a trait measure, responding to how much a subject feels that their present state is unlike their usual state” (GHQ User's Guide, 1978).

Table 1 Prescribed Scoring Methods for GHQ-12

\begin{tabular}{|l|l|l|}
\hline GHQ Scoring method & $\mathbf{0 - 0}-\mathbf{1}-\mathbf{1}$ \\
\hline Likert Scoring method & $0-1-2-3$ \\
\hline $\begin{array}{l}\text { Chronicity GHQ (CGHQ) Scoring method } \\
\text { (Duncan-Jones 1985). }\end{array}$ & For Positive items & For Negative items \\
\cline { 2 - 3 } & $0-0-1-1$ & $0-1-1-1$ \\
\hline
\end{tabular}

Out of these three scoring methods the researcher preferred Likert scoring method because it produces less skewed score distribution than prescribed General Health Questionnaire scoring method.

\section{RESULTS}

Table 2 Mean, SD and Standard Error

\begin{tabular}{|l|c|c|c|c|}
\hline & N & Mean & Std. Deviation & Std. Error \\
\hline JCOs & 35 & 14.200 & 3.9093 & .6608 \\
\hline Other_ranks & 35 & 11.886 & 3.6037 & .6091 \\
\hline Total & 70 & 13.043 & 3.9100 & .4673 \\
\hline
\end{tabular}

Table 3 ANOVA outcomes on Wellbeing (Psychological distress)

\begin{tabular}{|l|c|r|c|c|c|}
\hline & Sum of Squares & \multicolumn{1}{c|}{ df } & Mean Square & F & \multicolumn{1}{c|}{ Sig. } \\
\hline Between Groups & 93.729 & 1 & 93.729 & $\mathbf{6 . 6 3 1}$ & $\mathbf{. 0 1 2}$ \\
\hline Within Groups & 961.143 & 68 & 14.134 & & \\
\hline Total & 1054.871 & 69 & & & \\
\hline
\end{tabular}


Last held Military Rank and Wellbeing (Psychological Distress) of Army Ex-Servicemen (NonCommissioned Officers)

Table 4 Test of Homogeneity of Variances

\begin{tabular}{|c|c|c|c|}
\hline Levene Statistic & df1 & df2 & Sig. \\
\hline .001 & 1 & 68 & .974 \\
\hline
\end{tabular}

The data in Table 2 exhibits that $\mathrm{F}$ ratio (6.631) is significant at $\mathrm{p}<.05$. The rank as independent variable has differential effect on the wellbeing. The Levene's test of HoV consistently meets the homogeneity of variances assumption where Levene's test is not statistically significant at $\mathrm{p}<$ .05. The data inferences support the hypotheses that there is a significant difference between JCOs and Other_ranks (last held Military Rank) on wellbeing (psychological distress).

\section{DISCUSSION}

General wellbeing is a general health and happiness, combination of emotional, psychological, spiritual and physical being. The general wellbeing of ex-servicemen/veterans and soldiers has been studied, reported and defined (operationally) in terms of positive mental health (Amy, et al., 2015), professional success (Feist \& Barron, 1996), and combat exposure by (Brounéus, 2014). Further, the wellbeing was explored in terms of profession related mental problems such as PTSD (Carpenter, 2009; Brounéus, 2014; Meghan E. et al., 2014 \& Williston, et al., 2015), psychological fatigue, distress, depression, alcohol dependency syndrome, anxiety, combat stress (Pemberton, 2012) and undeclared social bracketing (Verma, 2016). The soldier faces more or less similar predicament in context of wellbeing across nations as soon as he hangs up his uniform voluntarily of compulsorily. The findings suggest that 'Rank' has significant effect on the wellbeing of holder. Military rank system forms the backbone of behavioural soldier management. Rank being a prominent behavioural management tool has considerable effect is visible from the means score of the measure. The means score of JCOs on wellbeing measure is 14.2 and for Other_ranks it is $\mathbf{1 1 . 8 8 6}$. Higher means score of JCOs might be attributed to the fact that they stay longer with the institution which have its own requirements such as, demands of unyielding orders \& commands, regular exposure to intense violence, professional strain in context to performance, away from family life and irregular association with social bodies. Whereas, the Other_ranks have relatively lesser stay with the institution, subsequently have lesser behavioural impact of above said factors.

However, it is pertinent to mention here that the results of the study are required to be tested longitudinally across the country with larger samples drawn from the population of interest prior to generalization and ascertaining its’ validity and reliability.

\section{Acknowledgments}

The author appreciates all those who participated in the study and helped to facilitate the research process. 


\section{Last held Military Rank and Wellbeing (Psychological Distress) of Army Ex-Servicemen (Non- Commissioned Officers)}

\section{Conflict of Interests}

The author declared no conflict of interests.

\section{REFERENCES}

Adler, Amy B., Jason, Williams., Dennis, McGurk., Andrew, Moss. \& Paul, O. Bliese. (2005). Resilience training with soldiers during basic combat training: Randomization by platoon. Applied Psychology: Health and Well-being. 7(1), 85-107.

Brounéus, K., (2014). On return from peacekeeping: A review of current research on psychological well-being in military personnel returning from operational deployment. Department of Peace and Conflict Research. Sweden: Uppsala University.

Carol D. R. \& Corey, L. M. K. (1995). The structure of psychological well-being revisited. Journal of Personality and Social Psychology, (69) 4,719-727.

Feist, G. J., \& Barron, F. (1996, June). Emotional intelligence and academic intelligence in career and life success. Paper presented at the Annual Convention of the American Psychological Society, San Francisco.

Goldberg, D. \& Williams, Paul. (1978, 1992). A user's guide to the general health questionnaire. London: nferNelson Publishing Company Ltd.

Hamlet-Trust. United Kingdom. Mental Health Information. (2009). An online United Kingdom based Mental Health Information Centre.

Louise, C. (2009). The Observer, February 1. The Mental Health Foundation, London, The Mental Health of Soldiers Returning from Conflict, (4)19.

Ministry of Veterans’ Affairs. (2008). Media Release. VA083. Australia.

Meghan, E., McDevitt-Murphy., James, G. M., Joah, L. W., Christopher, J. Monahan., K, L., Bracken-Minor., \& Jordan, A. F. (2014). Randomized controlled trial of two brief alcohol interventions for OEF/OIF veterans. Journal of Consulting and Clinical Psychology, 82(4), 562-568.

Pemberton, M. (2012). Combat Stress: Ex-Servicemen and Mental Illness. The Telegraph March 15.

Tonks, K. (2012). Ex-military service personnel (veterans) mental health and wellbeing provision in Kent \& Medway. A scoping report.

Verma, R. (2016). Undeclared social bracketing of ex-soldiers: A potential bottleneck for their successful transition. The International Journal of Psychology, (3)2, 85-91.

Williston, S. K., Casey. T. Taft. \& Kayla, O, Van Haasteren. (2015). Military veteran perpetrators of intimate partner violence: Challenges and barriers to coordinated intervention. Aggression and Violent Behaviour, 21, 55-60.

How to cite this article: R Verma, R Singh (2016), Last held Military Rank and Wellbeing (Psychological Distress) of Army Ex-Servicemen (Non-Commissioned Officers), International Journal of Indian Psychology, Volume 3, Issue 4, No. 64, ISSN 2348-5396 (e), ISSN: 2349-3429 (p), DIP: 18.01.135/20160304, ISBN: 978-1-365-32519-9 